\title{
Fostering Inquiry and Creativity in Early Years STEM Education: Policy Recommendations from the Creative Little Scientists Project
}

Fani Stylianidou 1*, Esme Glauert ${ }^{2}$, Dimitris Rossis ${ }^{1}$, Ashley Compton ${ }^{3}$, Teresa Cremin ${ }^{4}$, Anna Craft ${ }^{4}$, Sari Havu-Nuutinen ${ }^{5}$

\author{
${ }^{1}$ Ellinogermaniki Agogi, GREECE \\ ${ }^{2}$ Institute of Education, University College London, UNITED KINGDOM \\ ${ }^{3}$ Bishop Grosseteste University Lincoln, UNITED KINGDOM \\ ${ }^{4}$ The Open University, UNITED KINGDOM \\ ${ }^{5}$ University of Eastern Finland, FINLAND
}

*Corresponding Author: fani@fani-stylianidou.org

Citation: Stylianidou, F., Glauert, E., Rossis, D., Compton, A., Cremin, T., Craft, A. and Havu-Nuutinen, S. (2018). Fostering Inquiry and Creativity in Early Years STEM Education: Policy Recommendations from the Creative Little Scientists Project. European Journal of STEM Education, 3(3), 15. https://doi.org/10.20897/ ejsteme/3875

Published: September 6, 2018

\begin{abstract}
Creative Little Scientists was a 30-month (2011-2014) EU/FP7-funded research project focusing on the synergies between early years science and mathematics education and the development of children's creativity, in response to increasing interest in these areas in European educational policy. Using a variety of methods, including desk research, a teacher survey and classroom-based fieldwork, the research provided insights into whether and how children's creativity is fostered and appropriate learning outcomes, including children's interest, emerge. Based on these and ongoing collaboration and dialogue with participants and other stakeholders the project proposed recommendations for policy and teacher education. This paper presents these recommendations and the research on which they were based. Throughout the study, mixed methods were employed, combining quantitative approaches used in surveys of policy and teachers' views based on a list of factors, alongside qualitative approaches employed in case studies of classroom practice. A strong conceptual framework developed at the start of the project guided data collection and analysis, as well as the presentation of findings and the development of policy recommendations, thus ensuring the latter's strong and consistent relationship with the relevant theoretical knowledge, the comparative research, analysis of classroom practices and the production of guidelines for teacher education.
\end{abstract}

Keywords: science, mathematics, education, policy, creativity, inquiry, early years

\section{INTRODUCTION}

Creative Little Scientists (CLS) project was a 30-month EU funded comparative study working across nine participating countries: Belgium, Finland, France, Germany, Greece, Malta, Portugal, Romania and the UK. The project sought to build a picture of policy and practice in science and mathematics education for children aged 38 and their potential to foster creativity and inquiry learning and teaching.

The project aimed to add to previous EU reports in science and mathematics education in its focus on the nature of science and mathematics education in the early years and in seeking to characterise and investigate opportunities for creativity in learning and teaching. It aimed to mainstream good practices by proposing changes in 
teacher education and classrooms encompassing curriculum, pedagogy and assessment. A significant strand of the project was therefore the development of recommendations for policy and teacher education building on findings from the study and ongoing collaboration and dialogue with participants and other stakeholders. This paper presents these recommendations and the research on which they were based.

\section{BACKGROUND, OBJECTIVES AND FRAMEWORK}

\section{Core Drivers for Creative Little Scientists}

The project was informed by four key drivers for an increased research focus on science and mathematics education and creativity in early years education:

- The role of an economic imperative within education, demanding capable scientists and creative thinkers in an increasingly knowledge-based globalised economy (European Commission, 2011), requiring capabilities such as reasoning skills, innovative thinking and positive attitudes.

- The role played by science, mathematics and creativity in the development of children and of citizens, demanding early understanding and interaction with phenomena in nature and technology, which empower students (and therefore future adults) to take part in societal discussions and decision-making processes (Gago et al., 2004; Harlen, 2008).

- The role of early years education in building on cbildren's early experiences and in promoting positive skills and dispositions (Sylva, 2009), informed by increased awareness of the child as an active and competent meaning-maker, who can take ownership of their own learning and take part in decision making in matters that affect their lives in the present (Goswami, 2015).

- The role of a digital or technological imperative within education, enabling but also demanding the development of children's capabilities in science, mathematics and creativity (Wang et al., 2010).

\section{Objectives for Creative Little Scientists}

In the light of the above, the Creative Little Scientists project set the following objectives:

- To define a clear and detailed Conceptual Framework comprising the issues at stake and parameters that needed to be addressed in all stages of the research.

- To map and comparatively assess existing approaches to science and mathematics education in preschool and first years of primary school (up to the age of eight) in the nine partner countries, highlighting instances of, or recording the absence of, practices marrying science and mathematics learning, teaching and assessment with creativity.

- To provide a deeper analysis of the implications of the mapped and compared approaches, which would reveal details of current practice and provide insights into whether and how children's creativity is fostered and the emergence of appropriate learning outcomes in science and mathematics achieved.

- To propose a set of curriculum design principles as concrete guidelines for European initial teacher training and continuous professional development programmes, which would foster creativity-based approaches to science and mathematics learning in preschool and the first years of primary education. The proposed principles would be accompanied by illustrative teacher training materials examining their applicability in complex and varied European educational contexts, thus facilitating implementation, evaluation and further development across Europe.

- To exploit the results of the research at European, national and institutional levels, making them easily available to educational policy makers and other stakeholders, through synthesis of research outputs and their transformation into a 'Final Report on Creativity and Science and Mathematics Education for Young Children' (Creative Little Scientists, 2014a) and also a 'Set of Recommendations to Policy Makers and Stakeholders' (Creative Little Scientists, 2014b).

\section{Conceptual Framework for Creative Little Scientists}

The first of these project objectives was achieved through extensive reviews of policy-related and researchbased literature at the beginning of the project covering diverse areas including science and mathematics education in the early years, creativity in education, creativity as a lifelong skill, teaching and teacher training approaches, as well as cognitive psychology and comparative education. The resulting Conceptual Framework (Creative Little Scientists, 2012a) provided a strong theoretical framework for the study. Two particular features of the Conceptual Framework played key roles in fostering coherence and consistency in approach across the project and in themselves have the potential to contribute to future work in the field, the definition of creativity in early science and 
mathematics employed across the project and the synergies identified between inquiry based and creative approaches to learning and teaching (see Cremin et al., 2015).

The definition of creativity in early science and mathematics, which was developed from the Conceptual Framework and subsequently refined through discussion with stakeholders, is: Generating ideas and strategies as an individual or community, reasoning critically between these and producing plausible explanations and strategies consistent with the available evidence. This needs to be understood alongside the 'Little c creativity' definition (Craft, 2001) - "Purposive, imaginative activity generating outcomes that are original and valuable in relation to the learner" - insofar as this effort toward originality and value through imaginative activity drives creativity in early science and mathematics.

An influencial factor cutting across the existing traditions or paradigms for understanding and researching creativity is the location of creativity in early childhood at the 'everyday' end of the spectrum from 'little c' or everyday creativity (Beghetto and Plucker, 2006; Craft, 2003; Runco, 2003) to 'big c' or paradigm-changing creativity (e.g. Gardner, 1993; Csikszentmihalyi, 1996; Simonton, 1994). According to Craft (2001), "Little c creativity' [ ] focuses on the resourcefulness and agency of ordinary people, rather than the extraordinary contributions and insights of the few" (p49). For early years education this is important as "most creative children do not make major contributions to a field; rather, they produce useful or good products that are novel and good 'for their age group"' (Russ and Fiorelli, 2010: 234). Another way in which this contrast has been described is as 'personal' creativity rather than 'historical' creativity (Boden, 2001, 2004). Creativity is characterised as at the heart of what it is to be human by Robinson (2001), who emphasised the need for finding one's own passion (Robinson, 2009) so as to make something of one's life. This notion of creativity as self-creating also underpins Craft's $(2001,2010)$ perspective on the guiding force of 'little c' creativity in learners' lives.

The Conceptual Framework for Creative Little Scientists also explored synergies and differences between inquirybased (IBSE) and creative approaches (CA) to science and mathematics. Although definitions of IBSE vary, there is considerable agreement internationally, reflected in both policy and research, about the value of inquiry-based approaches to science education (Minner et al., 2010). CA, on the other hand, does not refer to a recognised set of approaches to education and learning, but nonetheless characteristics of such approaches have gained considerable attention in research and policy contexts in recent years (Chappell et al., 2008). Both IBSE and CA are pedagogically associated with a range of child-centred philosophies from European and North American thinkers, which situate the child as an active and curious thinker and meaning maker and highlight the role of experiential learning. Common synergies identified are:

- Play and exploration, recognising that playful experimentation/exploration is inherent in all young children's activity, such exploration is at the core of IBSE and CA in the Early Years (see e.g. Goswami, 2015; Cremin et al., 2006; Poddiakov, 2011).

- Motivation and affect, highlighting the role of aesthetic engagement in promoting children's affective and emotional responses to science and mathematics activities (see e.g. Craft et al., 2012; Koballa and Glynn, 2008).

- Dialogue and collaboration, accepting that dialogic engagement is inherent in everyday creativity in the classroom, plays a crucial role in learning in science and mathematics and is a critical feature of IBSE and CA, enabling children to externalise, share and develop their thinking (see e.g. John-Steiner, 2000; Mercer and Littleton, 2007).

- Problem solving and agency, recognising that through scaffolding the learning environment children can be provided with shared, meaningful, physical experiences and opportunities to develop their creativity as well as their own questions and ideas about relevant concepts (see e.g. Cindy et al., 2007; Craft et al., 2013).

- Questioning and curiosity, which is central to IBSE and CA, recognising across the three domains of science, mathematics and creativity that creative teachers often employ open ended questions, and promote speculation by modelling their own curiosity (see e.g. Chappell et al., 2008).

- Reflection and reasoning, emphasising the importance of metacognitive processes, reflective awareness and deliberate control of cognitive activities, which may be still developing in young children but are incorporated into early years scientific and mathematical learning and IBSE (see e.g. Kuhn, 1989; Bancroft et al., 2008).

- Teacher scaffolding and involvement, which emphasises the importance of teachers mediating the learning to meet the children's needs, rather than feel pressured to meet a given curriculum (see e.g. RittleJohnson and Koedinger, 2005; Bonawitz et al., 2011).

- Assessment for learning, emphasising the importance of formative assessment in identifying and building on the skills attitudes, knowledge and understandings children bring to school; supporting and encouraging children's active engagement in learning and fostering their awareness of their own thinking and progress (see e.g. Harrison and Howard, 2011; Feldhusen and Ban, 1995). 


\section{RESEARCH APPROACH AND DESIGN}

\section{Research Questions and Approach for Creative Little Scientists}

The Creative Little Scientists project aimed to identify and characterise evidence of creativity in early science and mathematics (in relation to policy, teachers' pedagogy and children's learning) and to outline implications for policy, practice and teacher education. Its research questions were:

RQ 1. How are the teaching, learning and assessment of science and mathematics in Early Years in the partner countries conceptualised by teachers and in policy? What role if any does creativity play in these?

RQ 2. What approaches are used in the teaching, learning and assessment of science and mathematics in Early Years in the partner countries? What role if any does creativity play in these?

RQ 3. In what ways do these approaches seek to foster young children's learning and motivation in science and mathematics? How do teachers perceive their role in doing so?

RQ 4. How can findings emerging from analysis in relation to questions 1-3 inform the development of policy and practice in the classroom and in teacher education (Initial Teacher Education and Continuing Professional Development)?

The project's Conceptual Framework recognized three broad strands running across all these research questions that probe:

- Aims/purpose, aims and purposes of creativity in science and mathematics education; how science and mathematics are taught and learned in relation to other domains of knowledge; how these relate to inquirybased science education (IBSE); views of creativity in relation to perceived purpose.

- Teaching, learning and assessment, including inquiry learning activities, pedagogy and resourcing, also how children develop creative dispositions and how teachers assess them in early science and mathematics education.

- Contextual factors, including classroom, teacher and institutional factors.

These three strands were broken down into more narrowly-defined dimensions drawing on the framework of curriculum components 'the vulnerable spider web' (van den Akker, 2007, p.39), which focus on key questions about aspects of learning in schools: Rationale or Vision; Aims and Objectives; Learning Activities; Pedagogy (or Teacher Role); Assessment; Materials and Resources; Location; Grouping; Time; Content. These were complemented by dimensions focusing on aspects of teachers and teacher education.

Within these strands and dimensions a list of creativity enabling factors (List of Factors) were identified (Creative Little Scientists, 2012b), drawing on the Conceptual Framework and highlighting the common conceptual ground between creativity and inquiry based science and mathematics education. These factors were employed across the project to provide the scope and parameters for mapping and comparing existing conceptualisations in policy and practice, and to code current approaches observed in teacher pedagogy and children's learning.

Finally, the three strands, van den Akker's (2007) curriculum dimensions and the list of factors were also used as a basis for the development of the curriculum design principles for teacher education and recommendations for education policy makers and stakeholders ensuring strong and consistent relationships amongst theoretical knowledge established though the literature review, the comparative research, analysis of classroom practices and the production of the curriculum design principles and guidelines for teacher education.

\section{Research Phases and Methodology}

To meet the project's objectives and research questions, mixed methods were employed, combining quantitative approaches used in surveys, alongside qualitative approaches employed in fieldwork.

The First phase of the research focused on the comparative assessment of how early years science and mathematics is conceptualised by teachers and in policy in the nine partner countries, highlighting instances of, or recording the absence of, practices marrying science and mathematics learning, teaching and assessment with creativity. It thus addressed RQ1 and part of RQ4 above. The research used the methodology of comparative education employing common frameworks to inform instrument design and data analysis in making comparisons, drawing on data collected via two routes:

1. A desk survey of policy to examine how teaching, learning and assessment of science and mathematics in the early years are conceptualised in 134 national policy documents, including curricula, reports and assessments of school practice.

2. A teacher survey, which gathered data through a teacher questionnaire addressed to a sample of 815 teachers from 605 schools (238 preschools and 367 primary schools) across all partner countries, aimed towards gaining insights into practicing teachers' conceptualisations of science, mathematics and creativity in early years education. 
The planning of the two pieces of research commenced at the same time to achieve maximum coherence between the studies. In addition, as research instrument, they both used a similar 4-point Likert Scale questionnaire based on the curriculum components of Van den Akker (2007) and on the creativity and inquiry approaches identified in the List of Factors. In the case of the policy survey, the questionnaire aimed to assess the extent to which these approaches were emphasised in policy documents and how far the role of creativity was emphasised. In the case of the teacher survey, it aimed to assess the extent to and frequency with which teachers use these approaches in their classrooms. Aligning the two surveys facilitated subsequent comparison of their results.

The Second phase of the research focused on mapping the approaches used in teaching, learning and assessment of early years science and mathematics in partner countries and describing the subsequent development of young children's creativity and learning. It thus addressed RQ2, RQ3 and part of RQ4 above. Undertaken across four months, the project fieldwork focused on sites potentially offering 'exemplary practices' (defined in relation to insights derived from the project's literature reviews, Conceptual Framework and policy surveys) in fostering creativity and inquiry in early science and mathematics, covering preschool and early primary education provision in each country. The sampling, which was purposive, was informed by information gathered from the teacher surveys, school inspection reports, attainment records, local authorities and teacher education institutions.

The fieldwork was qualitative in nature, and conducted in 48 different sites across partner countries resulting in 71 case studies of practices in early science and mathematics. Each partner worked in at least four sites (i.e. preschools/schools), gathering data from at least six cases (i.e. one teacher/practitioner and the children they work with). Partners identified three episodes of activity per case encapsulating creativity in these domains which resulted in 218 narrative episodes for analysis. In order to capture rich data, the fieldwork encompassed multiple methods of data collection (including documents, observations, interviews, drawings, photos) designed to take account of different aspects of pedagogy and be sensitive to young children's learning.

As mentioned above, throughout both phases of the research, concepts from the project's Conceptual Framework (e.g. the definitions of creativity, children's creative dispositions, inquiry learning activities and the identified synergies between IBSE and CA), as well as the three broad strands (Aims/purpose; Teaching, Learning and Assessment; Contextual Factors), van den Akker's curriculum dimensions and the List of Factors were employed consistently to provide the scope and parameters for data collection and analysis, as well as for the development and presentation of the related teacher education guidelines and education policy recommendations building on research findings.

It was also recognized that policy and practice needed to be interpreted within partners' particular national contexts, especially when making comparative judgments. As a result, all phases of research were first reported in separate national reports, which were then synthesized to produce overall accounts and comparisons of policy and practice at European level, all available on the project's website (www.creative-little-scientists.eu). Consequently, policy recommendations were developed at both national and European levels, drawing on the corresponding research findings and informed by consultation with communities of stakeholders - teachers, student teachers, school staff members, teacher educators, researchers, policy makers and experts in the fields of inquiry, creativity or science/mathematics - in online and face-to-face national focus groups, as well as in discussion sessions set up for this purpose during the final international conference of the project.

The sections that follow summarise research findings and present these recommendations for policy development in early years science and mathematics education across Europe.

\section{SUMMARY OF RESEARCH FINDINGS}

\section{Conceptualisations of Teaching, Learning and Assessment of Science and Mathematics in Early Years - the Role of Creativity}

This section presents summary of research findings in relation to RQ1, concerning conceptualisations of teaching, learning and assessment in early years science and mathematics (and creativity in these), held by teachers and in education policy in the project countries (see Stylianidou et al., 2016).

\section{Aims and Putposes}

The explicit curriculum rationale in policy for science education in nearly all partner countries focused on children's role as citizens and highlighted science and environmental awareness as a part of their life in general; this was also reflected in teachers' views. However research findings revealed that teachers' viewpoints regarding the rationale for science learning was in practice more holistic than that found in the policy documents in partner countries. Learning aims and objectives were conceptualised by teachers as primarily contributing towards affective and social aspects of learning, such as increasing interest and positive attitudes towards science and science learning. These views contrasted with the emphasis in policy (especially in early primary education) on the 
development of knowledge and understanding of science and mathematics ideas and on process skills associated with scientific inquiry.

\section{Teaching, Learning and Assessment}

In terms of learning activities, specific features of inquiry were reflected in both teachers' views and policy guidance. Teachers in both preschool and early primary science and mathematics classroom made reference to inquiry based learning, a key part of the policy framing in all countries, in particular through learning activities associated with observation, questioning, communication and the use of simple tools. Yet, despite this general reference to inquiry based learning, teachers' responses rarely referred to inquiry activities related to practical investigations and using data to construct explanations.

In terms of conceptualisations about pedagogy teachers across the partner countries held a great appreciation for pedagogical approaches that promote dialogue and collaboration amongst children, although teachers often failed to see the potential of these approaches for the development of children's creativity. This was consistent with policy which put some emphasis on their importance, but included very limited reference to features of creativity that might be fostered through dialogue and collaboration and very limited guidance to support teachers in enabling creativity using classroom discussions and collaborative work.

There was an uneven treatment in both policy and teachers' reported practice of the approaches associated with the synergy motivation and affect. Learning approaches based on building on children's prior experiences or relating science and mathematics to everyday life were amongst those reported as most frequently used by teachers and referenced in policy, although they were not highlighted as 'creativity enabling' either by teachers or in policy documents. In contrast cross curricular approaches for example, making use of drama or history to teach science and mathematics were rarely promoted both by teachers and in curricula, which also failed to make reference to their potential for creativity.

There was a similarly uneven treatment of approaches with reference to the synergy play and exploration. Preschool teachers reported using open forms of play and role play significantly more than early primary school teachers, and a greater proportion of preschool teachers also conceptualised these as 'creativity enabling'. This was also reflected in preschool curricula across the partner countries, with policy in the majority promoting playful exploration in preschool considerably more than in primary education. On the other hand teachers and policies from both phases were in agreement in fostering children's physical exploration of materials, an approach also conceptualised as 'creativity enabling' by teachers and in policy, and especially for primary education.

Teachers, as well as policy guidance, emphasised teaching approaches linked to problem solving and agency across both phases of early years education. These approaches were also often suggested to foster children's creativity, particularly in preschool.

Learning approaches associated with questioning and curiosity and their importance in fostering creativity were similarly conceptualised by teachers and in policy guidance. Practices that encourage children to ask questions and foster their imagination were reported as frequently used by teachers, were emphasised in policy and were perceived by both as 'creativity enabling'. In contrast, the role of teacher questioning in supporting creative learning were given more limited recognition.

Learning approaches linked to fostering reflection and reasoning were perceived to have limited scope in promoting children's creativity by both teachers and in policy documents, though teachers reported using them quite or very frequently.

In terms of teachers' conceptualisations about scaffolding, teachers saw themselves as facilitators of children's own inquiry, delaying instruction until the learner had had a chance to investigate and inquire on their own or with others. They were a little more reticent to allow children to find solutions on their own, although they strongly rejected the suggestion that they should first act as demonstrators of the correct solution before children investigate for themselves.

Assessment, especially formative assessment, was widely highlighted as an important area for development in both policy and practice in both preschool and primary phases. Policy guidance in terms of both methods of assessment and criteria for assessing on-going progress was often found lacking, which is reflected in considerable variability in assessment approaches found across partner countries. A common tendency to focus on product instead of process in assessment, allied with the pressures of statutory summative assessment processes in a number of partner countries revealed a number of challenges related to assessment of inquiry and creativity. Whilst the assessment of science and mathematics was widely emphasised in policy, more limited attention was given to assessment of inquiry processes and procedural understanding, and even less to social and affective dimensions of learning across the majority of partner countries, even though these dimensions were often highlighted in the rationale and aims set out for early science and mathematics education. Teachers' responses to the survey regarding their priorities for science assessment on the other hand were consistent with the frequency with which they indicated pursuing the corresponding aims and objectives in their science teaching. 
Finally, there was very limited evidence in policy of a role for creativity either in the priorities or methods for assessment advocated. In particular, little attention was paid to multimodal forms of assessment or the involvement of children in assessment processes often associated with creative approaches to learning and teaching in the early years. Again here a contrast was noted between findings from the policy and teacher surveys as teachers reported taking account of children's multimodal expressions for assessment purposes, especially in preschool.

\section{Contextual Factors}

In general, limited advice was given in policy in terms of the physical and social environment for learning. Where advice on materials was provided, it mostly related to the provision of equipment for inquiry and use of digital technologies. There was very little emphasis on a budget for teaching or technical support for science. In terms of ways of grouping children for learning, common themes included the recommendation of a variety of approaches to suit particular tasks and learning needs and the benefits of collaborative learning.

Finally, fieldwork highlighted the important influence of wider contextual factors on the opportunities for inquiry and creativity. Episodes illustrated the positive impact of whole school philosophy in for example:

- provision of support for experiential and child-centred approaches to learning and teaching; attention to provision for learning in the whole school environment, both indoors and out;

- support for team working and for further professional development and scope for trying out new ideas.

In interviews with researchers, teachers made reference to a number of barriers in fostering inquiry and creativity in mathematics and science. Restrictions of space, time and curriculum requirements were often highlighted. Teachers in primary settings also noted that levels of staffing limited their use of the outdoor environment and their employment of a wider range of assessment strategies.

\section{Approaches Used in the Teaching, Learning and Assessment of Science and Mathematics in Early Years: Opportunities for Inquiry and Creativity}

This section presents summary of the findings in relation to RQ2.

\section{Aims and Purposes}

Finding from fieldwork indicated that in both preschool and primary settings there was a strong focus on social and affective factors of learning and the development of scientific and mathematical concepts and process skills was a common feature of episodes observed.

The aims of activities were often implicit. Where aims were made explicit, they rarely included a focus on creativity although the promotion of creative dispositions was evident in the majority of classroom episodes observed. Explicit focus on the nature of science was also limited.

\section{Teaching, Learning and Assessment}

Overall, in both preschool and primary settings considerable potential was found for inquiry and creativity in the opportunities teachers provided for the generation and evaluation of ideas and strategies. Opportunities for the generation of ideas, for example, were fostered by rich motivating contexts for play and exploration, whilst purposes for inquiry were linked to children's everyday experiences and there was considerable scope for children's decision making.

Dialogue and collaboration, promoted by widespread use of group work and teacher questioning, played important roles in encouraging the processes of reflection and explanation associated with the evaluation of ideas and strategies.

The potential of sensitive and responsive teacher scaffolding both to support independence and extend inquiry was underlined, particularly in relation to when to intervene and when to stand back in order to listen to and build upon children's creative engagement and the development of their ideas and questions.

Opportunities for play were limited in primary settings. The value of play and exploration in the primary age phase could be more widely appreciated, for example in generating ideas and questions and fostering a feel for phenomena.

Findings suggested that the roles of varied forms of representation and the processes of representation (not just the product) in developing children's thinking needed greater recognition; this included the role of ICT, particularly in preschool settings.

There were few examples of episodes involving the use of outdoor resources or non-formal settings for learning in museums or the wider community. Here differences were noted between preschool and primary settings. In a number of preschool settings, children had free access to outdoor areas, and the overall provision of space and staffing levels were more generous, providing greater scope for practical exploration.

Assessment approaches observed were generally informal and formative and were based on observation and teacher questioning. There was limited evidence of the involvement of children in assessment, although interviews with children during fieldwork did indicate their capabilities to reflect on their learning and gave new insights into learning processes. 


\section{Contextual Factors}

Findings underlined the important influence of teachers' wider perspectives on learning and teaching, and their views of the nature of science and mathematics and understanding of creativity on the aims and approaches explicit or implicit in the activities observed. Teachers in most settings designed their own learning experiences with only a small proportion of episodes relying on textbooks or published schemes, where this was observed it was most common in the teaching of mathematics.

Project partners commented on the greater scope for child-initiated activity and creative engagement in preschool settings, although this was not always recognised by teachers, and on the tendency for pressures of time and curriculum requirements to limit opportunities for children's creativity and inquiry in primary settings.

\section{Fostering Young Children's Learning, Interest and Motivation in Science and Mathematics}

This section presents summary of the findings in relation to RQ3 that is concerning the outcomes of the approaches described above in terms of children's inquiry skills and creative dispositions; and how teachers perceived their role in fostering these outcomes.

Across the episodes there were many examples of children observing and making connections, for example drawing on prior learning or between experiences. Opportunities for children's questioning were also present but not always recognised or built upon.

There was greater evidence of children's engagement in the social dimensions of inquiry, explaining evidence and communicating explanations than might have been expected from the findings of policy and teacher surveys; this was often prompted by dialogue with peers and adults.

Explicit examples of children's developing understanding of the nature of science were limited however starting points were indicated in a number of episodes, in children's reflections on learning in classroom discussion, or in interviews with researchers.

Children's inquiry skills and understandings noted in episodes were interconnected with evidence of a number of creative attributes. For example children's motivation, curiosity and abilities to come up with something new were evidenced in raising questions and in their active pursuit of explorations and investigations. The episodes reported offered many examples of children's sense of initiative and growing abilities to collaborate in deciding what to do in carrying out investigations. Children showed imagination, ability to make connections and thinking skills in offering explanations.

\section{How Did Teachers Perceive their Role in Doing So?}

Teachers involved in the case studies often indicated that they had not previously thought about the approaches they adopted in terms of opportunities for inquiry and creativity. Fieldwork processes had prompted reflection on the nature of inquiry and creativity in early science and mathematics and how this might be fostered.

Most teachers made reference to the importance of encouraging and supporting young children's engagement in early years science and mathematics as an important starting point for learning. Many emphasised the need to foster motivation and collaboration and provide a rich environment with space and time for exploration and problem-based learning, underlining key roles for teachers in encouraging reflection and making connections to promote children's conceptual understanding and the application of ideas in varied settings.

In sharing their approaches limited explicit reference was made to the role of creativity or to features of inquiry in science and mathematics.

\section{Future Development of Practice in the Classroom and in Teacher Education (ITE and CPD)?}

This section addresses RQ4, which suggested -based on the research findings above- the areas for attention in teacher education to support inquiry and creativity in early science and mathematics education. They included:

\section{Aims and Purposes}

- Perspectives on the nature of science and mathematics and the purposes of science and mathematics education in the early years.

- The characteristics and roles of creativity in learning and teaching in early science and mathematics.

\section{Teaching, Learning and Assessment}

- Approaches to planning at whole school and class levels to maximize scope and flexibility to foster children's inquiries and to provide opportunities for play and exploration (across both preschool and primary phases of education).

- Ways in which everyday learning activities can be opened up to allow space for children's agency and creativity.

- The roles of questioning in supporting inquiry and creativity; different forms of teacher questioning; ways of supporting children's questioning; recognising questions implicit in children's explorations. 
- Importance and roles of varied forms of representation, including the use of ICT, in supporting children's learning processes.

- Use of the outdoor and wider school environment for learning in science and mathematics.

- Assessment strategies and forms of evidence that can be used to support learning and teaching in early science and mathematics, the roles of peer and self-assessment.

\section{KEY RECOMMENDATIONS FOR POLICY DEVELOPMENT ACROSS EUROPE IN EARLY YEARS SCIENCE AND MATHEMATICS EDUCATION}

The recommendations for policy development are drawn from key findings from across the different phases of research summarised in the previous section. They are presented in relation to the key strands of importance in relation to opportunities afforded for inquiry, problem solving and creativity in early years science and mathematics: aims, teaching learning and assessment and contextual factors.

\section{Aims and Purposes}

The aims of the curriculum should:

1. Give greater recognition to young children's capabilities to engage with processes associated with evaluation as well as the generation of ideas in science and mathematics.

The review of policy noted a lack of coherence in policy in this aspect, for example a mismatch between rationale or aims that might emphasise the promotion of inquiry skills and creative dispositions, and assessment methods and criteria that allow limited opportunities for children to show their capabilities. Having said this, teachers needed help to recognise more fully young children's capabilities to engage with processes associated with the evaluation as well as generation of ideas in science and mathematics.

2. Foster the role of social and affective dimensions of learning and their connection with cognitive dimensions of learning such as engagement, evaluation skills and understandings related to the nature of science.

Across project countries social and affective dimensions of learning were given more limited attention in policy compared to cognitive dimensions. More particularly, the majority of policy documentation inspected lacked emphasis on promoting positive attitudes to learning and interest in early years science education.

\section{Teaching, Learning and Assessment}

Curriculum content and policy guidance should:

3. Emphasise the important roles of play-based approaches, child-initiated activity and practical investigation in both preschool and early primary school.

The project's Conceptual Framework considers playful experimentation and exploration is inherent in all young children's activity; such exploration is at the core of IBSE and CA in early years settings. Policy in the majority of project countries promoted playful exploration in preschool considerably more than in primary education, with guidance that suggests a recognition of its value in promoting creative skills and dispositions. It would be valuable to exemplify ways of creating such opportunities in the primary age phase within the greater constraints of time and curriculum requirements.

4. Give detailed attention to key features of problem solving and inquiry based learning and teaching particularly with regards to providing sufficient space and time in the curriculum for problem solving and inquiry to study areas in depth. Emphasise also the need for space and time for teachers to develop inquiry approaches and explore opportunities for creativity in learning and teaching in early science and mathematics.

Curriculum and assessment requirements, and space and time at school level can constrain teaching approaches, particularly in primary settings. Findings from fieldwork revealed pressures of time and curriculum requirements that drastically limit opportunities for children's creativity and inquiry in both settings. They also indicated that more flexible timetabling and the more holistic approaches to learning and teaching commonly associated with preschool settings allowed teachers greater flexibility to follow children's interests over time and to revisit experiences, making provision for children to encounter ideas in a range of contexts. The challenge here was often less one of time but of recognising and building on children's emerging interests, skills and creative ideas.

5. Include more explicit and detailed focus on the role of creativity in early science and mathematics. Provide explanation and illustration of the nature of creativity in learning and teaching in early years science and mathematics.

Findings from all research phases of the project suggest that a more explicit and detailed focus in policy on the role of creativity in early science and mathematics would be helpful. Where explicit references were made to 
creativity in policy they were often in very general terms without provision of guidance about what this might mean in the context of early science and mathematics. These need to be drawn out and exemplified to support teachers in translating policy priorities concerning creativity into specific classroom practices. Furthermore, while certain teaching approaches were often signaled as associated with creativity, such as problem solving and the use of digital technologies, there was limited indication of how such approaches might be used to foster creativity or inquiry.

6. Promote the role of inquiry activities in supporting the children's understanding of science ideas and nature of science. Give more attention to reflection and consideration of alternative ideas building on the social and collaborative features of learning and inquiry.

Approaches to teaching and learning associated with inquiry and creativity were widely included in policy guidance in partner countries. Connections to creativity were largely associated with the generation, rather than the evaluation of ideas. In seeking to foster opportunities for inquiry and a role for creativity, greater recognition could be given in policy to the roles of imagination, reflection and consideration of alternative ideas in supporting children's understanding of scientific ideas and procedures. Consideration of alternative ideas is also connected to social factors in learning and the provision of opportunities for development of understandings associated with the nature of science, on which explicit focus was found limited.

7. Recognise the importance and roles of varied forms of representation, including the use of ICT, in supporting children's learning processes.

The research indicates that the role of varied forms of representation in learning could be more widely recognised. While there were examples of children's employment of diverse forms of expression across the episodes, findings suggested that the range of approaches might be extended, in particular to incorporate children's greater use of ICT. They also indicated the value of dialogue with children about their recordings, and the potential of representation and expression, not just for recording outcomes, but for fostering reflection and reasoning processes.

8. Encourage meaningful and authentic contexts for inquiry, linked for example, to: events and experiences in everyday life; children's interests and concerns; questions emerging from cross-curricular projects or explorations; and issues in the wider environment beyond school.

Findings from the review of policy suggest that limited attention was given in policy to contexts for learning such as drama, stories, historical projects or everyday experiences in the environment. Exemplification would be valuable of the kinds of contexts teachers can provide, and ways of capitalising upon them to foster inquiry and creativity. Fieldwork findings indicated the important contribution of rich, motivating contexts in generating ideas, questions and interests, but also the need for teacher sensitivity to features of inquiry and emerging ideas implicit in young children's explorations, as well as for time and teacher flexibility to build on these.

9. Create coherence in assessment between the aims and objectives of learning and priorities in assessment. More attention should be given to social and affective and inquiry related issues in assessment guidelines.

A common theme to emerge across the research was the limited policy guidance for science assessment and inconsistencies in emphasis across different elements in curriculum policy, resulting in considerable variability in approaches adopted among project countries. For example while assessment of science ideas was widely emphasised in policy, limited attention was given to social and affective dimensions of learning, although these dimensions were often highlighted in the rationale and learning aims set out for early science and mathematics education and were greatly valued by teachers.

10. Foster the development of on-going assessment strategies and criteria for assessment to better reflect the emphasis on inquiry and creativity in the aims for science and mathematics in the early years.

Findings reflected lack of policy guidance in terms of both methods of assessment and criteria for assessing on-going progress. They also revealed particular challenges in assessment related to inquiry and creativity, linked to a common tendency to focus on product rather than process in assessment requirements, allied with pressures of statutory summative assessment processes. There was very limited evidence in policy of a role for creativity either in the priorities or methods for assessment advocated across project countries. Greatest emphasis was given to the assessment of science ideas. Understandings and competencies in relation to scientific inquiry were emphasised in assessment policy in a minority of countries and in only a few instances were attitudes a priority for assessment in science.

11. Provide further guidance on formative assessment approaches to support classroom practices. Assessment methods should be clearly linked to the multimodal approaches used in classroom practices. Policy statements should foster the use of children's involvement in assessment and provide increased opportunities to mirror the children's various strengths and opportunities in their learning.

While the importance of formative assessment has been increasingly recognised in policy, findings indicated that further guidance would be valuable to support classroom practices in assessment. Areas highlighted include: the use of multimodal forms of assessment to give young children opportunities to show best what they understand 
and can do; ways of involving children in peer and self-assessment to support children's reflection on inquiry processes and outcomes; and criteria to assess progression in learning, particularly in relation to inquiry and the development of dispositions associated with creativity.

\section{Contextual Factors}

Findings from across the project also identified a number of contextual factors of importance in fostering creativity and inquiry in early science and mathematics. Findings from the teacher survey and fieldwork in schools indicated there is a need to:

12. Ensure sufficient resources and facilities in schools to support practical inquiry and problem solving in early science and mathematics.

Across the research findings the project identified the influence of resources on the opportunities provided for inquiry and creativity in early science and mathematics. In some countries lack of resources was acknowledged as presenting an important challenge in implementing inquiry and problem-based approaches to learning and teaching. Need for further funding was found for example to support the use of ICT to extend children's problem solving and inquiry processes and the development of the whole school environment, in particular the outdoor environment to support learning.

13. Extend opportunities for ongoing professional development in early science and mathematics.

Access to Continuing Professional Development (CPD) was very varied across the project countries. Further recognition is needed of the value and importance of continued training and qualifications. Findings highlighted the need for knowledge and understanding of child development and early learning in science and mathematics to be included in teacher education programmes to support teachers in recognising and building on children's interests, ideas and explorations. The need for further training for teachers was identified in the use of the environment to support learning and teaching in science and mathematics, both the school environment indoors and out, and the wider environment and community beyond the school.

14. Encourage dialogue with parents and the wider community concerning the aims of science and mathematics education in the early years including the development of skills, processes and attitudes associated with inquiry and their roles in developing not just factual knowledge but long term understanding of concepts.

The different phases of the project have indicated opportunities provided in policy for promoting inquiry and creativity in early science and mathematics. However common challenges have also been identified associated with the demands of curriculum content and a focus on summative assessment in primary schools. Both can result in a focus on factual knowledge rather than deeper understanding and attention to outcomes at the expense of the development of skills, attitudes and processes associated with inquiry and creativity. In addition, a number of teachers across project countries have commented on the pressures they felt from parents to focus on factual knowledge and grades.

\section{Future Work}

Erasmus + funding enabled members of the consortium to take forwards the CLS project's curriculum design principles and guidelines for teacher education and create a teacher development course and accompanying teaching materials to be used in European teachers' professional development to promote the use of creative approaches in teaching science in preschool and early primary education, in the frame of inquiry-based educational environments (Creativity in Early Years Science Education project, www.ceys-project.eu).

\section{ACKNOWLEDGEMENTS}

The authors would like to acknowledge the work of all partners in the consortium.

\section{FUNDING}

The Creative Little Scientists project (2011-2014) received funding from the European Union's Seventh Framework Programme (FP7/2007-2013) under grant agreement number 289081. 


\section{REFERENCES}

Bancroft, S., Fawcett, M. and Hay, P. (2008). Researching children researching the world. London: Trentham Books.

Beghetto, R. A. and Plucker, J. A. (2006). The relationship among schooling, learning, and creativity: "All roads lead to creativity" or "You can't get there from here"? In J. C. Kaufman and J. Baer (eds.), Creativity and reason in cognitive development. Cambridge: Cambridge University Press. pp. 316-332. https://doi.org/10.1017/CBO9780511606915.019

Boden, M. A. (2001). Creativity and knowledge. In A. Craft, B. Jeffrey and M. Liebling (eds.), Creativity in education. London: Continuum. pp. 95-102.

Boden, M. A. (2004). The creative mind: Myths and mechanisms, 2nd Ed. London: Routledge.

Bonawitz, E., Shafto, P., Gweon, H., Goodman, N. D., Spelke, E. and Schulz, L. (2011). The double-edged sword of pedagogy: Instruction limits spontaneous exploration and discovery. Cognition, 120, 322-330. https://doi.org/10.1016/j.cognition.2010.10.001

Chappell, K., Craft, A., Burnard, P. and Cremin, T. (2008). Question-posing and Question-responding: the heart of 'Possibility Thinking' in the Early Years. Early Years, 28(3), 267-286. https://doi.org/10.1080/09575140802224477

Cindy, E., Duncan, R. G. and Clark, A. C. (2007). Scaffolding and achievement in problem-based and inquiry learning: A response to Kirschner, Sweller and Clark 2006. Educational Psychologist, 42(2), 99-107. https://doi.org/10.1080/00461520701263368

Craft, A. (2001). Little c Creativity. In A. Craft, B. Jeffrey and M. Leibling. Creativity in Education. London: Continuum. pp. $45-61$.

Craft, A. (2003). Creative thinking in the early years of education. Early Years, 23(2), 147-158. https://doi.org/10.1080/09575140303105

Craft, A. (2010). Possibility Thinking and fostering creativity with wisdom: Opportunities and constraints in an English context. In R. Beghetto and J. Kaufman (eds.). Nurturing creativity in the classroom. Cambridge: Cambridge University Press. pp. 289-312. https://doi.org/10.1017/CBO9780511781629.015

Craft, A., Cremin, T., Burnard, P., Dragovic, T. and Chappell, K. (2013). Possibility thinking: culminative studies of an evidence-based concept driving creativity?, Education 3-13, 41(5), 538-556. https://doi.org/10.1080/03004279.2012.656671

Craft, A., McConnon, L. and Matthews, A. (2012). Creativity and child-initiated play: fostering possibility thinking in four-year-olds. Thinking Skills and Creativity, 7(1), 48-61. https://doi.org/10.1016/j.tsc.2011.11.005

Creative Little Scientists. (2012a). Conceptual Framework. D2.2. Lead Auth: A. Craft, T. Cremin, J. Clack, A. Compton, J. Johnston, A. Riley.

Creative Little Scientists. (2012b). List of Mapping and Comparison Factors. D3.1. Lead Auth: S. Havu-Nuutinen, F. Styliannidou.

Creative Little Scientists. (2014a). Final Report on Creativity and Science and Mathematics Education for Young Children. D6.5. Lead Auth.: F. Stylianidou and D. Rossis.

Creative Little Scientists. (2014b). Set of Recommendations to Policy Makers and Stakeholders. D6.6. Lead Auth.: D. Rossis and F. Stylianidou.

Cremin, T., Burnard, P. and Craft, A. (2006). Pedagogy and possibility thinking in the Early Years. Journal of Thinking Skills and Creativity, 1(2), 108-119. https://doi.org/10.1016/j.tsc.2006.07.001

Cremin, T., Glauert, E., Craft, A., Compton, A., Stylianidou, F. (2015). Creative Little Scientists: exploring pedagogical synergies between inquiry-based and creative approaches in Early Years science. Education 3-13, 43(4), 404-419. https://doi.org/10.1080/03004279.2015.1020655

Czikszentmihalyi, M. (1996). Creativity: Flow and the psychology of discovery and invention. New York: Harper Perennial.

European Commission. (2011). Science education in Europe: National policies practices and research, Education, Audiovisual and Culture Executive Agency EACEAE9 Eurydice, Brussels.

Feldhusen, J. F. and Ban, G. E. (1995). Assessing and accessing creativity: An integrative review of theory, research and development. Creativity Research Journal, 8(3), 231-247. https://doi.org/10.1207/s15326934crj0803_3

Gago, J. M., Ziman, J., Caro, P., Constantinou, C., Davies, G., Parchmann, I. et al. (2004). Increasing human resources for science and technology in Europe. Report Luxembourg: Office for Official Publications of the European Communities.

Gardner, H. (1993). Creating minds. New York, NY: Basic Books.

Goswami, U. (2015). Children's Cognitive Development and Learning. York: Cambridge Primary Review Trust.

Harlen, W. (2008). Science as a key component of the primary curriculum: a rationale with policy implications. Perspectives on Education: Primary Science 1. Welcome.

Harrison, C. and Howard, S. (2011). Issues in primary assessment: Assessment for learning; how and why it works in primary classrooms. Primary Science, 116, 5-7. 
John-Steiner, V. (2000). Creative collaboration. New York: Oxford University Press.

Koballa, T. J. and Glynn, S. M. (2008). Attitudinal and motivational constructs in science learning. In SK Abell and NG Lederman (eds.), Handbook of research on science education. New York: Routledge. pp. 75-102.

Kuhn, D. (1989). Children and adults as intuitive scientists. Psychological Review, 96(4), 674-689. https://doi.org/10.1037/0033-295X.96.4.674

Mercer, N. and Littleton, K. (2007). Dialogue and the development of children's thinking: A sociocultural approach. London: Taylor and Francis.

Minner, D. D., Levy, A. J. and Century, J. (2010). Inquiry-based science instruction: What is it and does it matter? Results from a research synthesis years 1984 to 2002. Journal of Research in Science Teaching, 47(4), 474-496. https://doi.org/10.1002/tea.20347

Poddiakov, N. (2011). Searching, experimenting and the heuristic structure of a preschool child's experience. International Journal of Early Years Education, 19(1), 55-63. https://doi.org/10.1080/09669760.2011.571000

Rittle-Johnson, B. and Koedinger, K. R. (2005). Designing knowledge scaffolds to support mathematical problem solving. Cognition and Instruction, 23(3), 313-349. https://doi.org/10.1207/s1532690xci2303_1

Robinson, K. (2001). Introduction. In K. Robinson, (ed.) Out of Our Minds: Learning to be Creative. Chichester: Capstone.

Robinson, K. (2009). The element. How finding your passion changes everything. London: Allen Lane.

Runco, M. A. (2003). Education for creative potential. Scandinavian Journal of Educational Research, 47(3), 317-324. https://doi.org/10.1080/00313830308598

Russ, S. W. and Fiorelli, J. A. (2010). Developmental approaches to creativity. In: J. C. Kaufmann and R. J. Sternberg (eds.) The Cambridge Handbook of Creativity, pp. 234. Cambridge handbook of creativity. New York, NY: Cambridge University Press. pp. 233-249. https://doi.org/10.1017/CBO9780511763205.015

Simonton, D. K. (1994). Greatness: Who makes history and why. London: Guilford Press.

Stylianidou, F., Glauert, E., Rossis, D., Havu-Nuutinen, S. (2016). 'Creative Little Scientists' Project: Mapping and Comparative Assessment of Early Years Science Education Policy and Practice. In N. Papadouris, A. Hadjigeorgiou, C. Constantinou (Eds.), Insights from Research in Science Teaching and Learning. Selected Papers from the ESERA 2013 Conference. Contributions from Science Education Research, Vol. 2, pp. 201-220. Springer, Cham. https://doi.org/10.1007/978-3-319-20074-3_14

Sylva, K. (2009). Early Childhood Matters: Evidence from the effective pre-school and primary education project. London: Taylor and Francis.

van den Akker, J. (2007). Curriculum design research. In T. Plomp \& N. Nieveen (eds.), An Introduction to Educational Design Research. Axis Media-ontwerpers, Enschede.

Wang, F., Kinzie, M. B., McGuire, P. and Pan, E. (2010). Applying Technology to Inquiry-Based Learning in Early Childhood Education. Early Childhood Education Journal, 37(5), 381-389. https://doi.org/10.1007/s10643-0090364-6 